\title{
UNIVERSITY TUTORING ACTIONS USING AN INTEGRATED ONLINE PLATFORM
}

\author{
Cecilia Fissore, Francesco Floris, Marina Marchisio and Sergio Rabellino \\ University of Turin, Italy
}

\begin{abstract}
University tutoring consists of a set of heterogeneous actions aimed to support students, upon entering the University and throughout their academic life. The tutoring implements the resources needed to cope with possible difficulties in each phase of the training process. It also provides information and advice to better address the study course, prepares paths for the recovery of learning gaps, and provides assistance for the preparation of the thesis. Its main purpose is to remove any possible obstacles to a profitable attendance at courses, also through initiatives related to the attitudes and needs of individuals. The research group of University of Turin has designed and developed a model of online tutoring, carried out via an online Moodle platform integrated with a web conference service for the Disciplinary Tutoring of the University of Turin. The main aim of the project, called TutoratoOnline, is to reduce the number of students starting the second academic year with a low number of passed exams, by helping students with the lessons they find more difficult. Through the platform, various and many synchronous and asynchronous tutoring activities were offered to students. The aim of this paper is to discuss and analyze the multiple tutoring activities carried out through the platform and the multiple teaching strategies used, and to discuss how their variety is associated with a greater students engagement.
\end{abstract}

\section{KEYWORDS}

E-learning, Integrated Online Platform, Online Tutoring, University Tutoring, Virtual Learning Environment

\section{INTRODUCTION}

University tutoring involves a heterogeneous set of actions aimed to support students throughout their academic life, implementing the resources to face possible difficulties in each phase of the training process. The university tutoring must also give information and advice to better address the study course, prepare paths for the recovery of learning gaps, and provide assistance for the preparation of the thesis. Its main purpose is to remove any obstacles to a profitable attendance at courses, also through initiatives related to the attitudes and needs of individuals (Giuliani et al., 2015). Each University organizes their own tutoring model according to their needs and possibilities. New trends and challenges in the world of education invite to experiment with new learning paradigms based on blended and collaborative models, which involve active learning (Felder and Brent, 2009) and which stimulate the development of higher cognitive abilities indicated by the Bloom taxonomy (Krathwohl, 2002). These teaching approaches, such as Problem-Based Learning, Task-Based Learning, Project-Based Learning and Cooperative Learning, are the result of the characteristics and developments of the Information and Communication Age (Bozzo, 2012). At the same time, the use of ICT and computer networks to support training processes is constantly growing and a variety of educational approaches have emerged that uses the online tools as a virtual space capable of hosting a collaborative learning community. In particular, the evolution of online tutoring shows that success does not only depend on the tool selected to create the virtual learning environment, but also on the acquisition of a new culture that considers these practices as a further possibility and not in antagonism or as an alternative to face-to-face training (Trentin, 2003; Turrentine and Macdonald, 2006). In the academic year 2016/2017 the University of Turin enhanced the existing tutoring activities (disciplinary tutoring in attendance, reception activities for first year students, study assistance for enrolled students, advice on the training offer and study plans, support in finding information on international mobility) by offering students an online tutoring service. The main objective of this project, called "TutoratoOnline", is to reduce the number of students starting the second academic year with a low number of exams passed, helping students in the lessons which they may find more 
difficult. The online tutoring model that the research group of University of Turin has designed and developed is based on a student-centered didactic and blended approach, which combines traditional face-to-face classroom tutoring with online platform activities. The tool we chose to offer all the tutoring activities is the Moodle Virtual Learning Environment. The University of Turin carried out multiple experiences in the field of tutoring and adaptive teaching (Barana et al., 2017b; Barana et al., in press 2019; Barana et al., 2019a; Barana et al., 2019b), e-learning (Brancaccio et al., 2016; Brancaccio et al., 2019; Marchisio et al., 2019a) and in the development of Virtual Learning Environments (Barana et al., 2017a; Bruschi et al., 2018; Marchisio et al., 2019b). The research group also designed and developed the online Moodle platform of the project (available at the link: https://tutoratoonline.orientamente.unito.it/) integrated with a web conference service for the Disciplinary Tutoring of the University of Turin. On the platform students are offered synchronous and asynchronous support for 55 courses of 25 different bachelor's degree courses, adopting a blended learning approach that combines traditional face-to-face classroom tutoring with online platform activities. The aim of this paper is to discuss an analyse the multiple tutoring activities carried out through the platform and the multiple teaching strategies used, and to discuss how their variety produces a greater engagement of students.

\section{THEORETICAL FRAMEWORK}

Student-centered learning is an educational approach focused on each student's interests, abilities and learning styles. According to this theory, learning is not so much the transmission of knowledge from the teacher to the student, as an active process of acquiring the most suitable principles and strategies to achieve one's goals. This knowledge process, in which the teacher acts as a facilitator of learning, can be carried out through a wide range of activities, including dialogue and experience (Bozzo, 2012). The characteristics of a constructivist learning environment are: the centrality of the student's role, the functionality of the teacher as a facilitator rather than a source of knowledge and the stimulation of motivation and autonomous investigation. Student-centered learning requires students to be active and responsible participants in their own learning. A pedagogical approach close to constructionism is an experiential learning. This approach is able to integrate the theoretical and practical elements of learning into a vision that emphasizes the importance of the student's active and responsible contribution and the value of direct experience. Constructivism, student-centered learning and experiential learning provide interesting guidelines for the creation of personalized and strongly located learning paths. Johnson et al. (2012) present the adaptation of pedagogical models to new forms of communication and research, as well as the production and publication of information, and the massive introduction of new media technologies in all disciplinary and professional fields as significant challenges for education. The analysis by Johnson et al. on third-level education perspectives identifies as key trends the growing expectation of a collaborative and delocalized use of information technologies, the proliferation of electronic resources, the increase in the establishment of contacts and mediated relations from computer, and consequently the revision of the roles of teacher and student. In the last years, the use of e-learning technologies has increased considerably, making possible new learning methodologies based mainly on Virtual Learning Environments, which are increasingly customizable (Impedovo et al., 2011). Virtual Learning Environments, such as the Moodle Learning Management System, allow to have a learning environment that fulfills the constructivist and experiential ideal: it allows students to create and publish their own works, immediately usable and shared within the community, to compare the work and to actively collaborate with the teacher or other students.

Historically, online tutoring began with emailing, but this model of tutoring, as well as the face-to-face lesson, suggested to the student that each question had to be answered with a direct answer. According to a constructivist perspective, the purpose of training should not be a mere communication of knowledge, but it should include a set of educational actions which ensure that each student can identify the knowledge they need. The same can be done for tutoring actions: we could include a review of theoretical contents but also reflection activities, group discussions, development of students' learning with the use of concept maps, correction of exercises, test simulations in preparation for the exam and discussions on concepts, principles and critical skills (Ferreira M., 2013). When students evaluate their own learning, learning becomes an incentive and they become active agents of their own learning. With the availability of new tools, new tutoring models can be used, in both asynchronous and synchronous formats, in which the student does not 
only passively receive explanations but tests himself to evaluate its knowledge and skills. With online tutoring models, space and time problems can be solved (Turrentine and Macdonald, 2006). For example, we consider those cases where the space-time unity becomes a big obstacle to participating in a training event, or when e-learning methods prove to be more effective because they allow dismounting and separately playing the two components -"space" (I do as much as possible on my own, perhaps assisted remotely or involved in a learning group) and "time" (when the conditions on their border allow it). The online tutoring also allows to engage students who cannot take part to the face-to-face activities, as well as working students, thus involving a higher number of students and offering all students the same possibilities.

\section{TUTORING THROUGH THE ONLINE PLATFORM}

Basing on this theoretical framework, the research group of University of Turin has designed and implemented a model of tutoring for the Disciplinary Tutoring of the University of Turin, in the "Tutorato Online" project. The first experimental edition of the project (2017-2018) involved a small number of courses and included exclusively online tutoring activities (Barana et al., 2018). The activities were in synchronous form - upon agreeing the day and time with the tutor, students had the possibility to fix an online appointment to have explanations on a specific topic and they could also connect to online tutorials requested by other students to listen to explanations; moreover, in asynchronous form, students had the possibility to ask questions and doubts in a forum and to submit writing, exercises or problems and have them corrected. In the second edition of the project (2018-2019), tutoring activities were activated for 55 courses of 25 different disciplines, for a total of 81 collaborations carried out by 77 tutors. The tutors were mainly graduates, and in some cases undergraduates, of the Master Degree. The small gap between the age of tutors and students helps in the action of tutoring and in achieving these objectives, since students are much closer in age to the tutors than to the teachers (Giraudo et al., 2014). The tutors followed a 3 hours course on the use of the Moodle Learning Virtual Environment and on the use of the Adobe Connect web conferencing service, so that they were able to work independently with the students creating their virtual learning communities. The tutors also received a 2 hours pedagogical training on the role of the tutor. In this second edition, we chose to use a blended learning approach also including face-to-face tutoring, in order to develop a model that could adapt to the different types of teaching involved (in which students are not used to using technologies during their studies) and in order to support and encourage students to use the platform. All the tutoring activities (face-to-face or online) were carried out using the platform, so as to take advantage of all its potential and have a complete tracking of the participation of the students. All the students of the University of Torino can access the platform with their UniTo credentials, then check if the course they are interested in is on the platform and, if so, register for the tutoring. A special dashboard was designed and developed by the research group in order to facilitate the search for the course (Barana et al., 2018). When students enrol in a course, they are asked to fill in a short questionnaire. The questions in the initial questionnaire are: Name and surname, Degree courses, Which year are you registered? (first/second/third/supplementary years), Have you already tried to take this exam? (Yes No), If yes, how many times? (One, Two, Three, More than three times).

Since all the courses on the platform belong to the first year of the three-year degree courses, but are in fact accessible to all students independently of the year, the initial questionnaire allows an overview of the students enrolled in the various tutoring courses. The format of tutoring courses is composed of an introduction to the course, where information is given about the teaching, the initial questionnaire, a forum for tutor communications and a forum for student requests. Each course has four sections, one for each type of activity: face-to-face tutoring, online tutoring, task delivery, teaching material.

Synchronous activities:

- Face-to-face tutoring: the tutor gives a lesson to a group of students according to a shared calendar, or offers a private consultation upon request. The platform is used to publish the tutoring calendar and to remind students of the appointment, to alert them of program changes or to request an appointment from the tutor through the forums. In addition, students are required to book their face-to-face tutoring, through the Moodle "Reservation" activity. In this way the tutor can know how many students will there be in the classroom, thus planning the teaching activity accordingly, and use the list of students to prepare the signature sheet. 
- Online tutoring: similar to the face-to-face tutoring, but it takes place entirely online via the Adobe Connect web conference tool, through which the tutor has the possibility to share the screen of his PC and the audio with the participants during the online meetings.

Asynchronous activities:

- Online tutoring through forums: the tutor answers the questions asked by the students, requests for further information or assistance with the use of the platform.

- Task submission: in this section there is an assignment activity, always open, which enables a teacher to communicate tasks, collect work and provide grades and feedback. The tutor can decide to set up tutoring activities through exercises to perform and submit and therefore use more delivery tools with specific availability. Students can submit exercises or papers and have them corrected by the tutor.

- Test/Teaching material: in this section the tutor makes available to the students tests for the consolidation of knowledge in preparation for the exam, as well as teaching material of his own creation, validated by the teaching professor before publication.

Each tutor, together with the teaching professor, was able to choose which tutoring activity to carry out (choosing only one, more than one or all of them) based on the characteristics of the teaching, the needs of the students and the type of final exam. They could also choose to carry out tutoring activities in parallel with the lessons, at the end of the lessons, before the exams or after the exams, to help the students who did not pass the exam. At the beginning of the project they had to present the program of tutoring actions but, in case of need, they could modify it during the project. The platform also hosts a community of tutors who, within the training course, can talk to each other about the activities carried out and refer to the managers of the platform for any doubts on the use of the Moodle platform. This course is also used for monthly reporting of tutors and monitoring of student attendance at tutoring activities. To access the platform, any mobile devices (tablet, smartphone) or a PC can be used. Lastly, the platform has an integrated HelpDesk service managed and monitored by the research group, to offer support to all its users (for example access problems, questions on how to use the platform, etc.). The helpdesk service is always active.

\section{METHODOLOGIES}

The platform currently counts 4899 registered users. In this paper we have considered only the second edition of the project, in which 3329 students enrolled in a tutoring course. Several data were used to study the multiple tutoring activities carried out through the platform and the multiple teaching strategies used, and to discuss how their variety is linked to greater student engagement: subdivision of the number of students enrolled in the 55 tutoring courses on the platform, answers to the initial questionnaire in each course completed by the students, activities carried out by students at the courses registered through the Moodle logging system and tutoring activities carried out in the various courses. To classify the activities carried out by tutors in the various tutoring courses, the Excel summary file of all the activities reported by the 77 tutors in the 81 collaborations was analysed. The reported activities were compared with the activities present in the course. The classification of the courses was made after the project ended. To derive the number of students enrolled in each course and the number of each student's logs the block "Configurable Reports" was used, a Moodle custom reports builder suitable for admins or teachers. This block allows the creation of custom reports, such as courses reports - with information regarding courses - users reports - with information regarding users and their activity in a course - and custom SQL Reports to create your own type of reports. The R software was used to analyze the 3329 students responses to the initial questionnaire and to perform statistical tests.

\section{RESULTS}

Each Study Course of the University of Turin has identified the courses in which the students had the most difficulty in taking the final exam. 55 courses of 25 different Study Courses were identified, belonging to 5 different Departments. There were 55 tutoring courses, one for each teaching. The types of teaching involved (Figure 1) can be divided into 3 macro-categories: linguistic (7), scientific (21) and humanistic (27). 


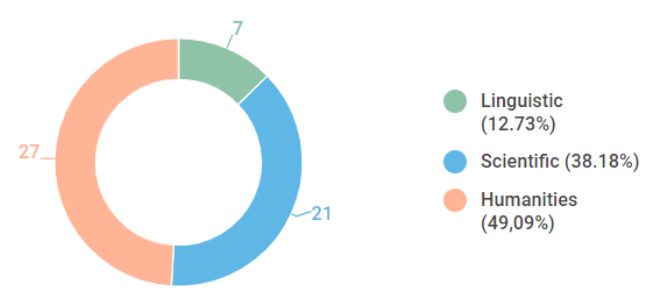

Figure 1. Types of courses involved for tutoring

To get an overview of which tutoring activities were used, we classified each course according to the four types of tutoring activities: face-to-face tutoring, online tutoring, task submission, test/teaching material. In the overview shown in table 1 , there is an " $\mathrm{X}$ " when an activity has been carried out and for each case the number of tutoring courses is reported. This first classification shows that in most courses more than one tutoring activity was used. Most courses have chosen to have face-to-face tutoring but in blended mode, alternating it with online activities. A good number of courses also carried out online tutoring. Ten courses held exclusively face-to-face tutoring and three courses held exclusively online tutoring.

Table 1. Overview of the type of tutoring activity proposed in the tutoring courses

\begin{tabular}{|c|c|c|c|c|}
\hline \multicolumn{4}{|c|}{ Type of tutoring activity } & \multirow{2}{*}{$\begin{array}{l}\text { Number of tutoring } \\
\text { courses }\end{array}$} \\
\hline Presence tutoring & Online tutoring & Task submission & Test/Teaching material & \\
\hline $\mathrm{X}$ & & & $\mathrm{X}$ & 15 \\
\hline $\mathrm{X}$ & & $\mathrm{X}$ & $\mathrm{X}$ & 10 \\
\hline $\mathrm{X}$ & & & & 11 \\
\hline $\mathrm{X}$ & $\mathrm{X}$ & $\mathrm{X}$ & $\mathrm{X}$ & 5 \\
\hline $\mathrm{X}$ & & $\mathrm{X}$ & & 6 \\
\hline $\mathrm{X}$ & $\mathrm{X}$ & $\mathrm{X}$ & & 2 \\
\hline \multirow[t]{2}{*}{$\mathrm{X}$} & $\mathrm{X}$ & & $\mathrm{X}$ & 2 \\
\hline & $\mathrm{X}$ & $\mathrm{X}$ & $\mathrm{X}$ & 2 \\
\hline \multirow[t]{2}{*}{$\mathrm{X}$} & $\mathrm{X}$ & & & 1 \\
\hline & $\mathrm{X}$ & & $\mathrm{X}$ & 1 \\
\hline
\end{tabular}

The analysis of the data of the initial questionnaire compiled by the 3329 students enrolled in a platform course (Figure 2) shows that, as expected, most of the students are enrolled in the first year, but there are also, students of the following years and students of supplementary years. All students completed the questionnaire only once, so no student enrolled in more than one tutoring course. Out of 3329 students, 796 students have already tried to take the exam of the chosen tutoring course: 447 once, 194 twice, 67 three times and 88 more than three times.
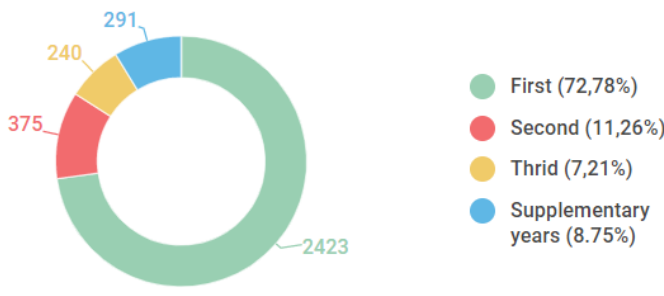

Figure 2. Students' answer to the question "Which year are you registered in?" of the initial questionnaire

Table 2 shows the connection between the two questions "Which year are you registered in?" and "Have you already tried to take this exam?", in each cell the absolute frequency, percentage, row percentage and column percentage are addressed. It emerges that a good number of first-year students enrolled in the tutoring course after failing the exam. Second and third year students are equitably split between those who had already taken the exam and those who had not yet taken the exam. It is interesting to note that there is a good percentage of supplementary years students who have never taken the exam. 
Table 2. Connection between the questions "Which year are you registered?" and "Have you already tried to take this exam?"

\begin{tabular}{cccc}
\hline & \multicolumn{3}{c}{ Already taken the exam } \\
\hline Year of course enrollment & No & Yes & Total \\
\hline Fist year & 2130 & 293 & 2423 \\
& 87,9 & 12,1 & \\
Second year & 84,1 & 36,8 & \\
& 194 & 181 & 375 \\
Third year & 51,7 & 48,3 & \\
& 7,7 & 22,7 & \\
& 101 & 139 & 240 \\
Supplementary years & 42,1 & 57,9 & \\
& 4,0 & 17,5 & \\
& 108 & 183 & 291 \\
Total & 37,1 & 62,9 & \\
& 4,3 & 23,0 & \\
& 2533 & 796 & 3329 \\
\hline
\end{tabular}

To analyze the engagement of students in the tutoring activities and the use of the platform, for each student registered on the platform we extracted the activities logs within the tutoring course. The tutors had a total of 40 hours (in the case of graduates) and 100 hours (in the case of students of the master's degree). They could use these hours for the whole duration of the one-year project. In some cases, the activities were concentrated only in some months of the academic year (close to the exams or in parallel with the lessons of the first or second semester) in other cases, tutors carried out activities for the entire duration of the project. The duration of the activities varies considerably, on average the tutoring face-to-face lessons lasted 2 hours but for the online activities the duration of the activities depended on the participation and the request of the students. As shown in Table 3, the range of Logs of 3329 students is very wide: there are students who have logged in very few times and have therefore hardly used the platform and students who have logged in many times and thus really took advantage of the platform. On average, a student logged in 95 times and the interquartile range - that is the width of the range of values containing the "central" half of the observed values - is 76. The first aspect we have studied is whether there is a correlation between the number of logs and the year of enrolment of the students previously analyzed. Since the Log distributions for the four groups "first year", "second year", "third year", "supplementary years" are not normal, we performed the non-parametric Kruskal-Wallis test to verify the equality of the medians. The value of the p-value is 0.005 and therefore there is sufficient statistical evidence to reject the hypothesis that the medians are equal for each group. Then we considered only two groups dividing students between "first year" and "subsequent years" and we studied if there is a correlation between the group and the number of Logs. With the Wilcox test we got a p-value of 0.6433 . The test therefore leads us to state that the median of the first year student logs is not statistically different from the median of the student log of the other years. This result confirms that, even if the courses were exclusively designed for the first year students, the students of the first year and subsequent years equally benefited of the tutoring service.

Table 3. Summary of Logs of course activity of all students

\begin{tabular}{cccccc}
\hline Min. & 1st Qu. & Median & Mean & 3rd Qu. & Max. \\
\hline 7 & 31 & 55,5 & 94,79 & 107 & 1975 \\
\hline
\end{tabular}

A second aspect that we have studied is whether the number of student Logs depends on the type of activities carried out during the tutoring course. We started from the subdivision of the courses into the four 
categories, shown in Table 1, grouping the last two cases into a single "online activity" case and creating the following new subdivision with the respective course numbers: "Only face-to-face and online without activity" ( 1), "face-to-face and online activities" (9), "only online with activities" (3), "face-to-face only with activities" (31) and "face-to-face only" (11). For each category we then divided the number of Logs of students enrolled in a course in that category into two classes "a few logs" and "many logs" depending on whether the value is less or more than the median of the Logs of that category (Table 4).

Table 4. Log classification in the various sub-categories of types of activities performed

\begin{tabular}{lcccccc}
\hline & $\begin{array}{l}\text { Presence and online } \\
\text { no activity }\end{array}$ & $\begin{array}{l}\text { Presence and online } \\
\text { with activity }\end{array}$ & $\begin{array}{l}\text { Online } \\
\text { activity }\end{array}$ & $\begin{array}{l}\text { Presence } \\
\text { activity }\end{array}$ & with & Only presence \\
\hline Few Logs & 1 & 1 & 1 & 15 & 9 \\
Many Log & 0 & 8 & 2 & 16 & 1 \\
\hline
\end{tabular}

To see if there is a correlation between the student logs and the use of online activities we have grouped these five categories into the two macro categories "online" (44) and "face-to-face" (11), where in the "face-to-face" category courses were included that only provided face-to-face tutoring. For the "online" category there are 26 courses in "many logs" and 18 courses in "a few logs", for the "face-to-face" category there are 10 courses in "a few logs" and a course in "many logs". The value of the p-value of the Fischer Test equal to 0.005 leads us to reject the independence between the type of course and the number of activities logs. This result confirms that in the courses in which we have a posteriori observed that only face-to-face tutoring was performed - without the use of online tutoring or platform activities -, the use of the platform was limited to make appointment with tutors and students were thus not encouraged to use the platform to ask questions in the forum or ask for corrections, meaning they did not take full advantage of its potential.
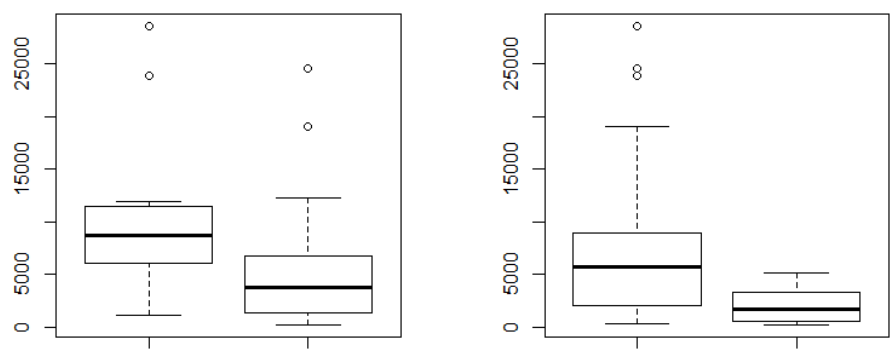

Figure 3. Boxplots of student Logs divided into the two categories: the 1st (left) and the 2nd (right)

We performed a new analysis with the two new macro categories "online2" (13) and "face-to-face2" (41), entering in the "online2" category all the courses that used the online tutoring (synchronous and asynchronous) and in the other all the courses that have not used it. We ran the Fisher test again to check the independence between the new course category and the number of activities logs. With this subdivision the value of the $p$-value greater than 0.05 indicates that the test does not provide any evidence against the assumption of independence. Comparison tests were then performed for the mean of the logs (Figure 3) between the two macro categories of courses for both classifications previously mentioned. In both cases there is statistical evidence that the average of the logs in courses classified as "online" is greater than the one of "face-to-face". This result shows, in the first case, that the use of online activities tailored to and at the request of the student stimulates the active engagement of the students. In the second case, since there is online activity in both categories, synchronous online tutoring seems to take on greater weight in the engagement of students.

\section{CONCLUSION}

The disciplinary tutoring carried out using the online platform made possible a blended tutoring, which alternated tutors, face-to-face or online, (synchronous and asynchronous) to asynchronous platform activities. The platform is used for all tutoring activities: synchronous activities (face-to-face tutoring and online tutoring) and asynchronous activities (online tutoring through forums, task submission, test/teaching material). In this way, a learning based on the needs and engagement of the student is promoted. The platform also made it possible to monitor the attendance of students in tutoring activities and that of the 
activities carried out by the tutors. 3329 students enrolled in a tutoring course. The analysis shows that all students, both in the first year and in the following years, actively participated in the tutoring activities and used the platform. It also emerged that student participation may depend on the type of activity performed, differentiating between online and non-online activities. At the end of the academic year an evaluation of the tutoring activities will also be conducted in relation to passing the final exams, using also psychological variables to explore the differences between users and non-users of the platform. The analysis of this paper shows the potential of tutoring activity through an online platform integrated with a web conference service.

\section{REFERENCES}

Barana, A., Bogino, A., Fioravera, M., Marchisio, M., Rabellino, S., 2017a. Open Platform of self-paced MOOCs for the continual improvement of Academic Guidance and Knowledge Strengthening in Tertiary Education. Journal of e-Learning and Knowledge Society 13, pp. 109-119.

Barana, A., Boffo, S., Gagliardi, F., Garuti, R., Marchisio, M., Empowering Engagement in a Technology Enhanced Learning Environment, in press 2019.

Barana, A., Fioravera, M., Marchisio, M., Rabellino, S., 2017b. Adaptive Teaching Supported by ICTs to Reduce the School Failure in the Project "Scuola Dei Compiti". Proceedings of 2017 IEEE 41st Annual Computer Software and Applications Conference (COMPSAC). IEEE, pp. 432-437.

Barana, A., Fissore, C., Marchisio, M., Rabellino, S., 2018. Online Tutoring to Enhance University Success. Exploring the Micro, the Meso and the Macro. Proceedings of the European Distanceand E-Learning Network 2018 Annual Conference. Genova, Italia, pp. 755-763.

Barana, A., Marchisio, M., Rabellino, S., 2019a. Empowering Engagement through automatic formative assessment. Proceedings of 2019 IEEE 43st Annual Computer Software and Applications Conference (COMPSAC), pp. 216-225

Barana A., Marchisio M., Sacchet M., 2019b. Advantages of Using Automatic Formative Assessment for Learning Mathematics. Draaijer S., Joosten-ten Brinke D., Ras E. (eds) Technology Enhanced Assessment. TEA 2018. Communications in Computer and Information Science, 1014. Springer, Cham, pp. 180-198.

Bozzo, L., 2012. Il blended learning all'Università: sperimentazione di un paradigma di apprendimento esperienziale costruttivista. Atti di Didamatica 2012.

Brancaccio, A., Esposito, M., Marchisio, M., Pardini, C., 2016. L'efficacia dell'apprendimento in rete degli immigrati digitali. L'esperienza SMART per le discipline scientifiche. MONDO DIGITALE 15, 10.

Brancaccio, A., Esposito, M., Marchisio, M., Sacchet, M., Pardini, C., 2019. Open professional development of math teachers through an online course. Proceedings of 13th International Conference on e-Learning. Porto, Portugal, pp. 131-138.

Bruschi, B., Cantino, V., Cavallo Perin, R., Culasso, F., Giors, B., Marchisio, M., Marello, C., Milani, M., Operti, L., Parola, A., Rabellino, S., Sacchet, M., Scomparin, L., 2018. Start@unito: a Supporting Model for High School Students Enrolling to University. Presented at the IADIS International Conference Cognition and Exploratory Learning in Digital Age 2018, pp. 307-312.

Felder, R.M., Brent, R., 2009. Active Learning: An Introduction. ASQ Higher Education Brief. Vol. 2, No. 4, pp. 1-5.

Giraudo, M.T., Marchisio, M., Pardini, C., 2014. Tutoring con le nuove tecnologie per ridurre l'insuccesso scolastico e favorire l'apprendimento della matematica nella scuola secondaria. Mondo Digitale 13, pp. 834-843.

Giuliani, A., Moretti, G., Morini, A., 2015. Servizi di tutorato didattico e Obblighi Formativi Aggiuntivi, un'indagine empirica esplorativa: il caso del Dipartimento di Scienze della Formazione dell’Università Roma Tre.

Impedovo, S., Campanella, P., Facchini, G., Pirlo, G., Modugno, R., Sarcinella, L., 2011. Learning Management Systems: un'analisi comparativa delle piattaforme open-source e proprietarie. Atti di Didamatica 2011.

Johnson, L., Adams, S., Cummins, M., 2012. The NMC Horizon Report: 2012 Higher Education Edition. The New Media Consortium, Austin, Texas.

Krathwohl, D.R., 2002. A Revision of Bloom's Taxonomy: An Overview. Theory Into Practice. Vol. 41, No. 4, $212-218$.

Marchisio, M., Operti, L., Rabellino, S., Sacchet, M., 2019a. Start@unito: Open Online Courses for Improving Access and for Enhancing Success in Higher Education. Proceedings of the 11th International Conference on Computer Supported Education (CSEDU 2019), pp. 639-646.

Marchisio, M., Sacchet, M., Salusso, D., 2019b. Instructional design to "train the trainers": the Start@unito project at the university of turin. Proceedings of 13th International Conference on e-Learning. Porto, Portugal, pp. 195-202.

Trentin, G., 2003. Gestire la complessità dei sistemi di e-learning. Atti del Convegno Didamatica 2003. Genova, pp. 1-8.

Turrentine, P., Macdonald, L., 2006. Tutoring Online: Increasing Effectiveness with Best Practices. NADE Digest Vol. 2, No. 2, pp. 9-18. 